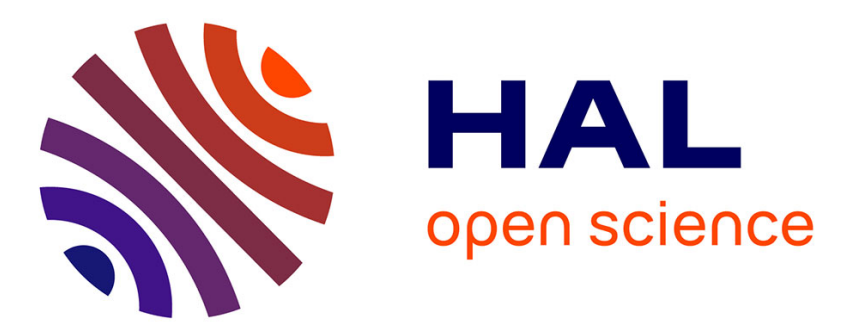

\title{
Attribution of Extreme Rainfall Events in the South of France Using EURO-CORDEX Simulations
}

\author{
L. Luu, R. Vautard, P. Yiou, G. van Oldenborgh, G. Lenderink
}

\section{To cite this version:}

L. Luu, R. Vautard, P. Yiou, G. van Oldenborgh, G. Lenderink. Attribution of Extreme Rainfall Events in the South of France Using EURO-CORDEX Simulations. Geophysical Research Letters, 2018, 45 (12), pp.6242-6250. 10.1029/2018GL077807 . hal-03230074

\section{HAL Id: hal-03230074 \\ https://hal.science/hal-03230074}

Submitted on 19 May 2021

HAL is a multi-disciplinary open access archive for the deposit and dissemination of scientific research documents, whether they are published or not. The documents may come from teaching and research institutions in France or abroad, or from public or private research centers.
L'archive ouverte pluridisciplinaire HAL, est destinée au dépôt et à la diffusion de documents scientifiques de niveau recherche, publiés ou non, émanant des établissements d'enseignement et de recherche français ou étrangers, des laboratoires publics ou privés. 


\section{Geophysical Research Letters}

\section{RESEARCH LETTER}

10.1029/2018GL077807

Key Points:

- The attribution of extreme rainfall events in the South of France is made by using model simulations and observations

- The change of extreme precipitation distribution is significant under climate change

- We verify the Clausius-Clapeyron relation for precipitation events

Supporting Information:

- Supporting Information S1

Correspondence to:

L. N. Luu,

linh.luu@lsce.ipsl.fr

Citation:

Luu, L. N., Vautard, R., Yiou, P., van Oldenborgh, G. J., \& Lenderink, G. (2018). Attribution of extreme rainfall events in the South of France using EURO-CORDEX simulations. Geophysical Research Letters, 45, 6242-6250. https:// doi.org/10.1029/2018GL077807

Received 12 MAR 2018 Accepted 12 JUN 2018

Accepted article online 19 JUN 2018

Published online 28 JUN 2018

(c)2018. American Geophysical Union. All Rights Reserved.

\section{Attribution of Extreme Rainfall Events in the South of France Using EURO-CORDEX Simulations}

\author{
L. N. Luu' ${ }^{1}$, R. Vautard' 1 , P. Yiou' ${ }^{1}$, , G. J. van Oldenborgh ${ }^{2}\left(\mathbb{D}\right.$, and G. Lenderink ${ }^{2}(\mathbb{D})$ \\ ${ }^{1}$ Laboratoire des Sciences du Climat et de I'Environnement, UMR 8212 CEA-CNRS-UVSQ, Université Paris-Saclay and IPSL, \\ Gif-sur-Yvette, France, ${ }^{2}$ Royal Netherlands Meteorological Institute (KNMI), De Bilt, Netherlands
}

\begin{abstract}
This study investigates how climate change affects the daily extreme precipitation events that occur in the autumn in Cévennes mountain range (South of France). We use an ensemble of 10 EURO-CORDEX model simulations with two horizontal resolutions $\left(0.11^{\circ}\right.$ and $\left.0.44^{\circ}\right)$. Those data sets, after pooling all models together, are fitted by stationary generalized extreme value and empirical distributions for several periods to estimate a climate change signal in the tail of distribution of extreme rainfall. We find that the exceedance probability of a 1-in-100-year event in the historical climate has increased by a factor of $2.5 \pm 0.8$ under the current climate. The results show that higher-resolution simulations with bias adjustment provide a robust and confident increase in the intensity and likelihood of occurrence of the events in the current climate in comparison with the historical climate. These changes are in agreement with an observations-based analysis in a previous study.
\end{abstract}

Plain Language Summary This paper investigates the connection between autumn high precipitation events in the South of France and climate change. From an ensemble of regional climate simulations and observations, we show that the probability of exceeding 100-year precipitation events has more than doubled, due to temperature increase.

\section{Introduction}

The Mediterranean region often undergoes thunderstorms in the autumn, which generate convective rainfall in coastal areas leading to more than $100 \mathrm{~mm}$ of precipitation in a day. Dedicated research programs have been devoted to understand these impactful phenomena (Drobinski et al., 2014; Ducrocq et al., 2014). In France, the Cévennes mountain range, which is located in the south of the country with its weather and climate strongly influenced by Mediterranean Sea, undergoes the highest amounts of daily precipitation in the autumn. In this region numerous extreme rainfall events in 2014 , one of them with an intensity of more than $300 \mathrm{~mm} /$ day occurring on different days, raised the question of the role of climate change in increasing likelihood and intensity of such events. Observations show a roughly $4 \%$ per decade increasing trend of autumn daily maxima over the past 60 years (Vautard et al., 2015). They also showed that the return period of 2014 amounts declined by a factor of 3 (95\% confidence interval: 1 to 13) since the middle of the twentieth century. This change was shown to be linked to the warming trend in the region. These results were later confirmed by an analysis over an extended region (Ribes et al., 2018). However, a formal attribution of this change to human influence on climate could not be done from an observational analysis only.

The attribution of such convective extreme precipitation events is emerging as a key challenge and has received substantial efforts in weather and climate sciences. Several previous studies have used large regions to aggregate events and infer human influence on past events. Min et al. (2011) showed a contribution of increased anthropogenic greenhouse gases (GHGs) to the intensification of convective rainfall events in the Northern Hemisphere using observation and multimodel simulation from Coupled Model Intercomparison Project phase 3, even though these models have resolutions of a few hundred kilometers and therefore cannot represent convective events. Zhang et al. (2013) determined the contribution of human influence on the increase in annual maxima daily rainfall and 5-day consecutive rainfall (i.e., Rx1day and Rx5day, respectively) over the Northern Hemisphere land areas. Those indices were analyzed by observations covering the period 1951-2005 and several coupled model simulations from the Coupled Model Intercomparison Project phase 5, again with resolutions of hundreds of kilometers. The results showed a 3.3\% increase in Rx1day with $90 \%$ uncertainty of $1.1 \%$ to $5.8 \%$ that is attributed to anthropogenic forcing. 
Fischer and Knutti (2015) showed that $18 \%$ of daily heavy rainfall events over continents can be mainly attributed to a human-induced warming trend since the preindustrial period.

Less robust results could be obtained in attributing extreme daily amounts over a limited region. However, Eden et al. (2016) used a multimethod approach to find higher confidence in the attribution of the extreme heavy rainfall event in September 2013 in Boulder (Colorado, USA). The authors determined the change in probabilities of the event in observations and an ensemble of two general circulation model simulations for daily amounts. Their results allowed them to draw a robust conclusion on the anthropogenic influence on such events. Van der Wiel et al. (2017) found the increase in both intensity and probability of annual maximum 3-day consecutive precipitation of heavy rainfall event in 2016 in the central U.S. Gulf Coast under 2016 climate conditions compared to 1900 climate conditions due to anthropogenic climate change. The results show strong confidence with a good agreement between observations and model simulation with multiple horizontal resolutions. In addition, the more realistic higher resolution model $(25 \mathrm{~km})$ produced a more significant increase in probability of the event of interest.

One of the issues that can be raised for short-lived convective rainfall attribution studies using climate models is that of resolution, as the phenomena involved have an intrinsically small scale. Recently, Prein et al. (2016) showed that the new EURO-CORDEX high-resolution $(12 \mathrm{~km})$ ensemble has a better ability to capture highprecipitation events in mountainous areas. Ruti et al. (2016) presented the results from the Med-CORDEX ensemble showing a clear improvement in extreme rainfalls in the mountain ranges surrounding the Mediterranean Sea with higher resolutions. This provides hope for better attributing the extreme daily events in the areas where orography plays a key role on such events.

In this article, we focus on the attribution of extreme Mediterranean rainfall using 14 stations in the Cévennes mountain range (as in Vautard et al., 2015) using EURO-CORDEX simulations. We verify that regional climate model simulations in the EURO-CORDEX project can reproduce statistical features of such events in the historical period and investigate their projections in future scenarios. This study completes the paper of Vautard et al. (2015), which was based on observations. The evaluations of model simulations of extreme rainfall are presented in section 2 . Section 3 shows the attribution of extreme rainfall events in the Cévennes range. Discussion and conclusions are drawn in section 4.

\section{Evaluation of Model Simulation of Extreme Events}

\subsection{Autumn Maxima Rainfall (Rx1day)}

We evaluate the ability of the models in simulating SON (September-November) daily maximum rainfall over the Cévennes mountain range. Three different data sets from EURO-CORDEX with six regional models driven by five different boundary conditions forming 10 simulations are investigated. The simulations were run under Representative Concentration Pathway 8.5 (Meinshausen et al., 2011) and cover the 1951-2100 period with two horizontal resolutions including 12 and $50 \mathrm{~km}$ (EUR-11 and EUR-44). For the finer resolution, we also use Cumulative Distribution Function transform (CDFt) bias-corrected simulations whose method was described in Michelangeli et al. (2009) and Vrac et al. (2012; ensemble denoted BC-EUR-11). Bias correction is made using the WFDEI reference gridded reanalyzes corrected by observations (Weedon et al., 2014). The detail of the 10 model simulations are given in supporting information Table S1. We use daily observational precipitation data of 14 stations in Cévennes mountain (Vautard et al., 2015) as reference.

We use quantile-quantile (q-q) plots to compare modeled SON rainfall maxima (Rx1day) with observations. From the gridded model data set, we use nearest neighbor interpolation to derive the simulation at 14 stations. This method avoids smoothing extreme values from a gridded model. Then, both SON rainfall values from models and observations are sorted in ascending order and compared for each station separately. Thus, the quantiles of each simulation at a station are compared to the observational quantiles. For each q-q plot between observations and models, we fit a linear regression $(Y=A X+B)$ to all the data points. In the regression, the model quantiles are considered as independent variables $(X)$ and observed quantiles are dependent variables $(Y)$. Ideally, the slope $(A)$ should be 1 and the intercept $(B)$ should be 0 . Those parameters (slope and intercept) indicate how the biases are distributed among models. An idealized linear model, with exponential distributions for the variables and a Gaussian perturbation with a standard deviation that is as large as the largest residual standard error of the fits described above, gives a $90 \%$ confidence 
[EUR-11] OBS $=A^{*}$ Model + B

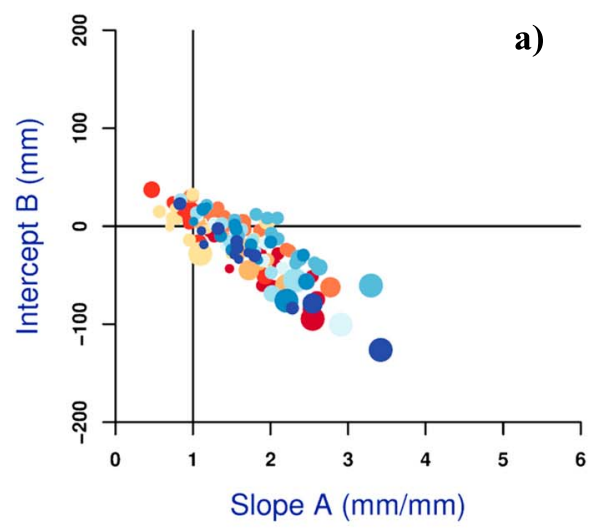

[BC-EUR-11] OBS $=A^{*}$ Model $+B$

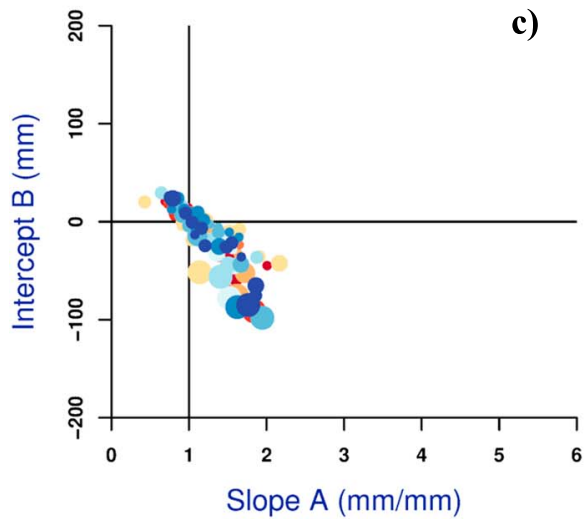

[EUR-44] OBS $=\mathrm{A}^{*}$ Model $+\mathrm{B}$

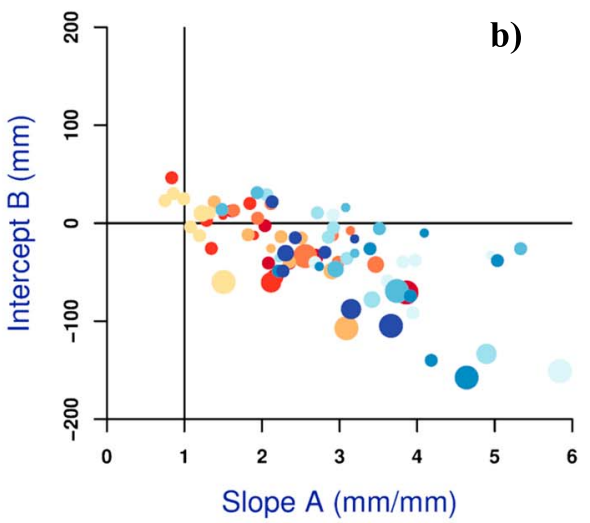

- CNRM-ALADIN53_CNRM-CERFACS-CNRM-CM DMI-HIRHAM5_ICHEC-EC-EARTH

IPSL-INERIS-WRF331F_IPSL-IPSL-CM5A-MR

KNMI-RACMO22E_CHEC-EC-EARTH

MPI-CSC-REMO2009_MPI-M-MPI-ESM-LR

SMHI-RCA4_CNRM-CERFACS-CNRM-CMS

SMHI-RCA4_ICHEC-EC-EARTH

SMHI-RCA4_IPSL-CM5A-MR

SMHI-RCA4_MOHC-HadGEM2-ES

Figure 1. Summary of q-q plot comparison of model and observation for the period of 1971-2005; colors denote different models, and size of dots denotes the residual standard error of the linear fit. The horizontal and vertical axes show the slope $A(\mathrm{~mm} / \mathrm{mm})$ and intercept $B(\mathrm{~mm})$ of the fit described in section 2.1. (a) EUR-11, (b) EUR-44, and (c) BC-EUR-11.

interval of 0.6 to 1.1 for the slope $(A)$ and -14 to 25 for the intercept $(B)$. This allows comparing how the simulation-observation regression differs from the ideal case.

Figure 1 summarizes the evaluation of the model skill in simulating SON Rx1day over 14 stations in the Cévennes region for the period of 1971-2005. For EUR-44, the slopes have much higher values than 1 (Figure 1b). Therefore, the simulated values of SON Rx1day are generally lower than the observations. We can point out the worst simulations in this case (RCA4 driven by IPSL-CM5A and MPI-ESM-LR). For EUR-11, the slope $A$ of the linear fit ranges from 0.5 to 3.5 (Figure 1a). This indicates a better agreement of model simulations to observations, in particular for the worst cases of EUR-44. The slope $A$ from BC-EUR-11 is in the range of 0.5 and 2, and approximately $10 \%$ of all models and stations show a slope lower than 1 (Figure 1c). As a result, most of the simulations tend to underestimate SON-Rx1day. In addition, we find that the residual standard errors range almost from 10 to $20 \mathrm{~mm}$ in the three model ensemble data sets.

\subsection{Dependence of Daily Rainfall on Temperature}

An increase in temperature raises the water capacity holding of the atmosphere with $6-7 \%$ per degree warming, following the Clausius-Clapeyron relation (Clapeyron, 1834; Clausius, 1850). This increase in water-holding capacity, and the fact that relative humidity changes are relatively small in climate change simulations, leads to the expected increase in heavy precipitation with warming. While the sensitivity of extremes to warming should be ideally derived from long climatic periods, deriving the dependency from short-term variability can also provide useful information (Lenderink \& Attema, 2015; O'Gorman, 2012; Westra et al., 2014). Therefore, we evaluate the models with a scaling method as described by Lenderink 

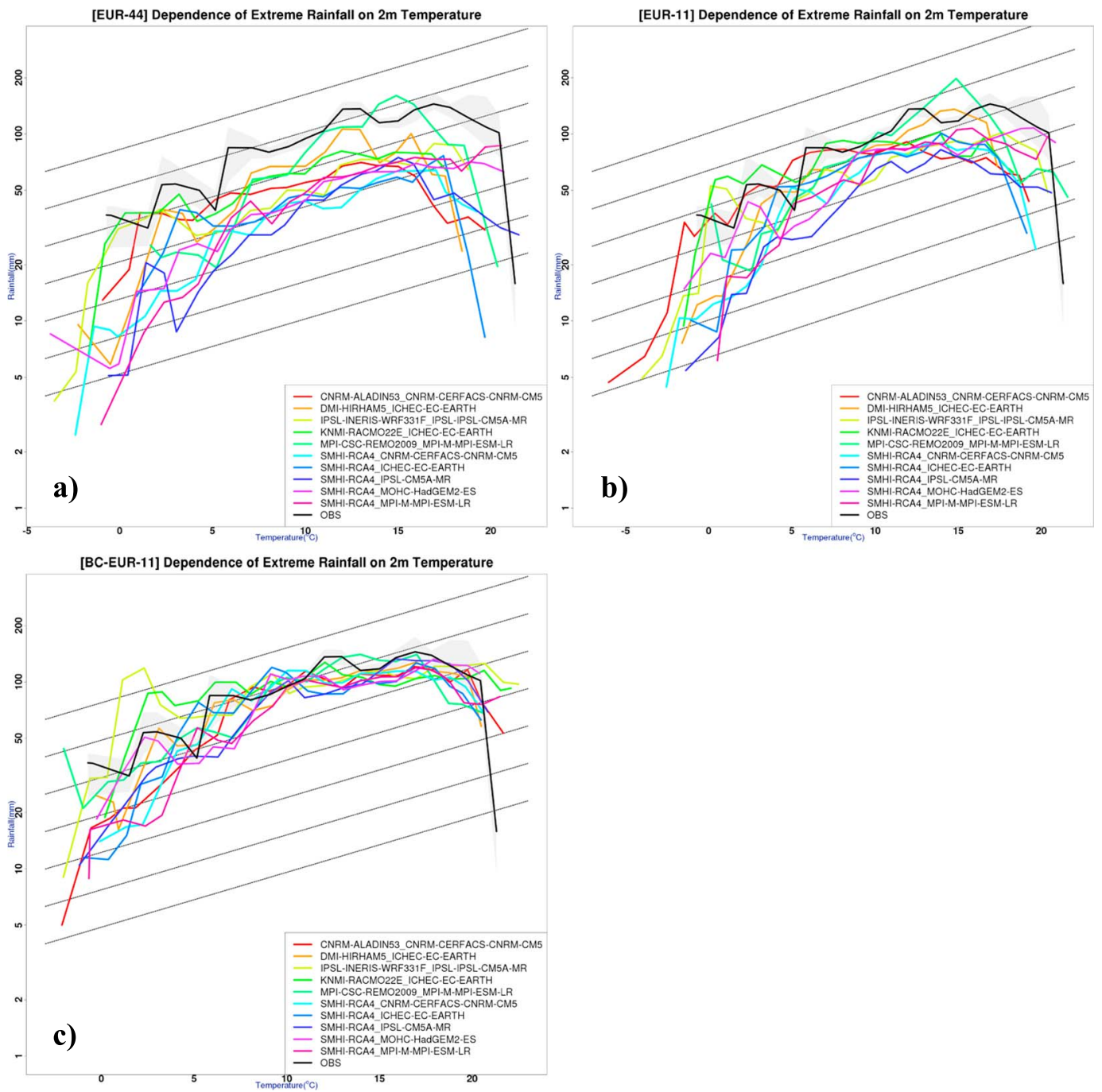

Figure 2. Dependency of extreme daily precipitation on 2-m temperature in the autumn (SON); (a) EUR-44, (b) EUR-11, and (c) BC-EUR-11; the gray bar shows $90 \%$ confidence interval of dependency from OBS; the dotted black lines denote Clausius-Clapeyron relation. SON = September-November.

and Van Meijgaard (2008) for the period of 1971 to 2005. This evaluation also enables us to confirm the attribution of change in extreme precipitation to human influence by linking it with temperature changes present in the model simulations, as was done by observations (Vautard et al., 2015). For this purpose, we pair daily mean temperature and precipitation at each station together and then pool all stations together. Then, this pooled data set is sorted in ascending order of temperature. Next, we divide the data into several bins with their width of $2{ }^{\circ} \mathrm{C}$ and $1{ }^{\circ} \mathrm{C}$ overlap between two successive bins as in Lenderink and Van Meijgaard (2008). In each bin, we calculate the 99th percentile of precipitation and the median of temperature of the bin. The $90 \%$ confidence interval is estimated by 2,000 nonparametric bootstrap samples. This analysis is conducted by using daily rainfall at 14 stations from observations and interpolated from the three model ensembles. For 2-m temperature, we compute the mean of a box bounded by $2.5-5^{\circ} \mathrm{E}$ and $43.5-45^{\circ} \mathrm{N}$ from the CORDEX ensembles and from ENSEMBLES daily gridded observational dataset (E-OBS) (Haylock et al., 2008).

Figure 2 shows extreme daily rainfall scaling with 2-m temperature from different simulations and observations. Table S2 presents the slopes of the linear fit to each curve in Figure 2, which gives the average increasing rate of daily rainfall following the increase in 2-m temperature. We find that the dependencies from observations follow the Clausius-Clapeyron relation for temperature ranging from 4 to $14{ }^{\circ} \mathrm{C}$ with an 

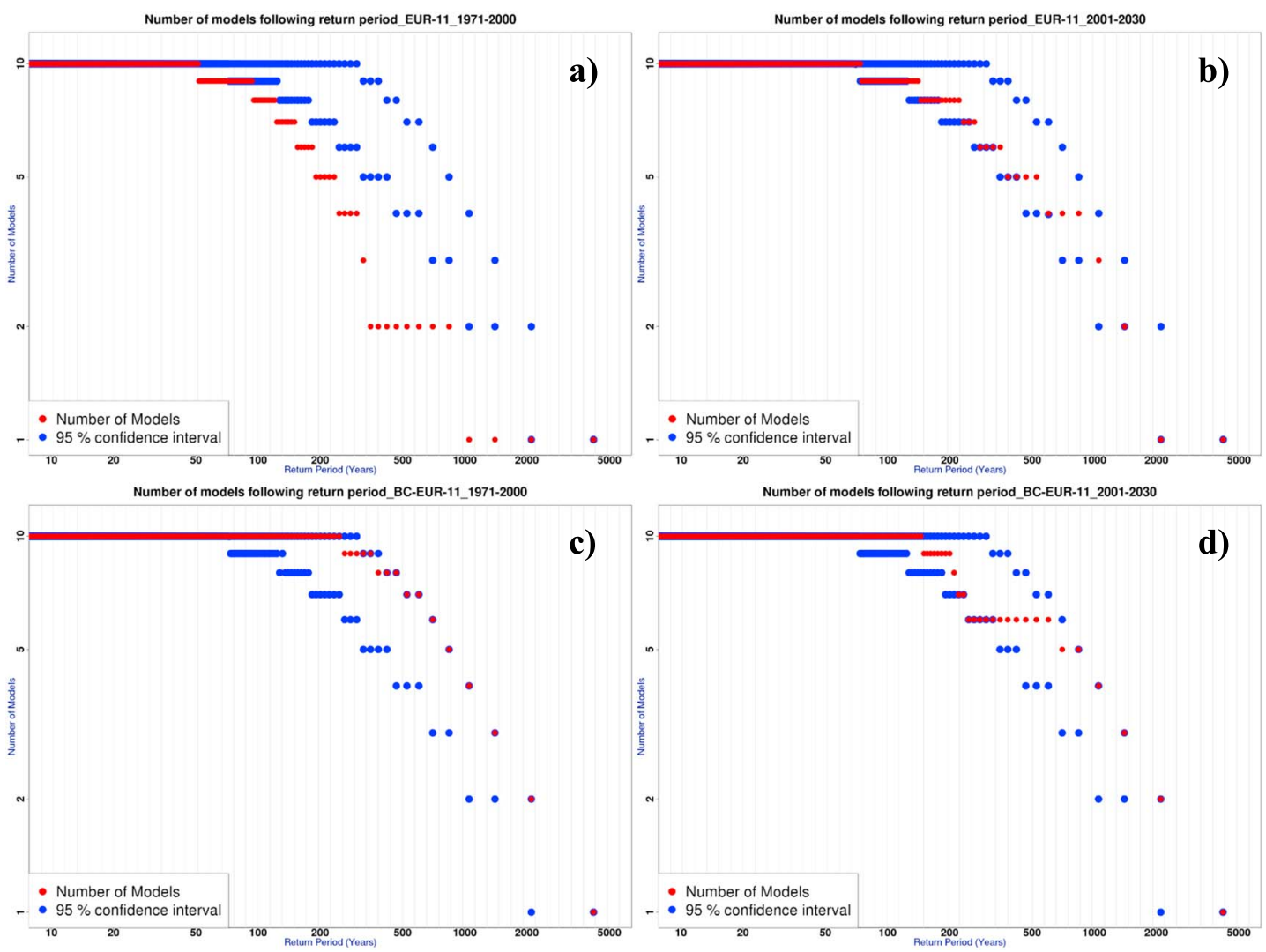

Figure 3. The number of models (red points) contributing to pooling distribution; the blue points denote $95 \%$ confidence interval from 1,000 nonparametric bootstrap sampling from complete pooled data sets; (a) historical and (b) current period of EUR-11; (c) historical and (d) current period of BC-EUR-11.

average increasing rate of $4.1 \% /{ }^{\circ} \mathrm{C}$. This rate is a bit lower than the $6-7 \% /{ }^{\circ} \mathrm{C}$ and also different from what was found for individual months in Vautard et al. (2015). This discrepancy could be due to the sensitivity of extreme rainfall response to warming being lower in mountainous regions where different dynamics control the vertical motion of air current (Shi \& Durran, 2016). Generally, the intensity of daily rainfall from EUR-44 is underestimated in comparison with observations. The best average dependent rate is $4.2 \% /{ }^{\circ} \mathrm{C}$ from ALADIN53 driven by CNRM-CM5 compared to $4.1 \% /{ }^{\circ} \mathrm{C}$ from observation. The intensity for rainfall from EUR-11 is also underestimated, and BC-EUR-11 has a better agreement with observation. The results of extreme rainfall intensity found here are consistent with what we found out in the previous section.

\section{Attribution of Extreme Events}

We pool together SON Rx1day from the 14 stations and 10 models from each ensemble separately for the historical (1970-2000) and current (2001-2030) climates, which are both scaled with observations over the historical period (i.e., each model value at a given station is multiplied by a historical fraction of the mean over time of all 14 observed stations divided by the mean over time of that model at that station) in order to obtain a pooled distribution that is as homogeneous as possible. We then make the assumption, as in Vautard et al. (2015), that this scaled and pooled data set represents a single distribution of daily rainfall events in the area. Events are, however, not independent from one station to another, a fact that is taken into account for confidence interval estimation (see below). Each 30-year model period is described by $14 \times 10 \times 30$ years of simulations, and the 58-year period of observations (1957-2014) is expressed by $14 \times 58$ years. The distribution of extreme precipitation of each period is modeled statistically by fitting a stationary generalized extreme value (GEV) distribution (Coles, 2001) to SON maxima daily precipitation (Rx1day) of pooled data for each ensemble. The $95 \%$ confidence interval is estimated by using bootstrapping with a moving block technique (Eden et al., 2016) in order to take into account the spatial dependence among 14 stations and the dependence among 10 models of each data set. For each bootstrap sample, we randomly pick values from the pooled 
data set that could be any model or station and also take all values from other models and stations that were highly correlated with the initial picked model and station. This allows us to take into account the correlation among stations and models, as was done in Vautard et al. (2015). The total size of each bootstrap experiment is 2,000 .

One question with model pooling is whether extremes are represented by only one or a few models with a significantly heavier tail than others, even after scaling or bias correction. To address this, we count the number of different models of the pooled data in the distribution tail corresponding to different return periods (Figure 3), and compare the curve obtained with the $95 \%$ confidence interval taken from 1,000 nonparametric bootstrap samples which were randomly drawn from complete pooled data sets. We count the number of models whose values are equal to or greater than a return value at a specific return period. For each return period, we repeat the same procedure 1,000 times to estimate the reference for comparison. We find that for the EUR-11 data set, the distribution tail includes an insufficient number of models as compared to random picking for return periods larger than about 100 years under the 1971-2000 climate, indicating heavier tails in some models than in others (Figure 3a). The BC-EUR-11 simulations do not seem to suffer from this potential problem after pooling, which is not surprising because the simulation distribution is corrected across the distribution. We also find the same result with EUR-44 data set (not shown) as for the historical climate from the EUR-11 data set.

The parameters of GEV fits of each data set are shown in Table S3. We find that the location and scale parameters increase in the current climate as compared to the historical climate for all three ensembles. These increases indicate that the distribution of extreme rainfall shifts toward higher level (location) and stretches (scale) more widely under the current climate in comparison with the historical climate. The shape parameter increases inducing a larger increase of time-dependent return values in the tail of distribution. Figure 4 shows return level plots for observations in 1957-2014, model historical simulations (1971-2000), model simulation of the current climate (2001-2030), and near (2021-2050) and far future (2041-2070). We discuss mainly the historical and current climate, which are assumed to represent counterfactual and factual climate, respectively. In attribution studies, we use factual climate terminologies to imply the world with anthropogenic effect where we are now, and counterfactual climate is of the world that might have been with only natural change and variability and the absence of human-induced climate change (i.e., preindustrial climate). We bear in mind that the historical period used still includes a significant amount of human forcing through GHGs and that most EURO-CORDEX simulations (i.e. except those from ALADIN and RACMO) only include changes in GHGs and not aerosols. We also note that global temperature under historical climate would be more or less $0.5^{\circ} \mathrm{C}$ higher than the preindustrial period.

The risk ratio is defined by the fraction between exceedance probability of rainfall events under current (factual) and historical (counterfactual) climate. These ratios represent the increase in likelihood of occurrence of extreme rainfall events in the factual climate and are summarized in Table S4 using three ensembles. For example, the YYYY-Years (column label in Table S4, e.g., 1,000-Years) implies the event with its intensity equal to or greater than 1,000-year return value at any among 14 stations in the counterfactual climate. Here we do not show the real return values corresponding to the return period because they are different among three data sets and two types of distributions including sorted (Empirical) and GEV-fitted pooling data set. We mainly discuss risk ratios and changes in rainfall intensity following empirical distribution because The GEV distribution seems unable to generate return values at large return period (Figure 4) for the three pooled data sets.

In the EUR-44 case (Figure 4a), the intensity of a 1-in-100-year event increases by $22 \%$ but with an extensive range of $5 \%$ to $36 \%$. Similarly, the likelihood of occurrence of a 1-in-100-year event of historical climate may have increased by a factor of 2.4 (1.3 to 4) under the current climate. This means that the event with intensity equal to or greater than 100-year return value in historical climate may occur every 40 years in the current climate at any among 14 stations (i.e., approximately 600 years at a given station).

The comparison between return level plots of historic and current climate EUR-11 is shown in Figure 4b. The intensity of a 1-in-100-year event in the historical climate may increase by $17 \%$ (1 to 27), and the likelihood of this event in the historical climate appears to increase by a factor of 2.2 (from 1.1 to 3.1) in current climate. For BC-EUR-11 (Figure 4c), the likelihood of occurrence of 1-in-100-year events between historical and current climate increases by a factor of 2.5 within a confidence range of 1.8 and 3.4. In addition, the magnitude of this 

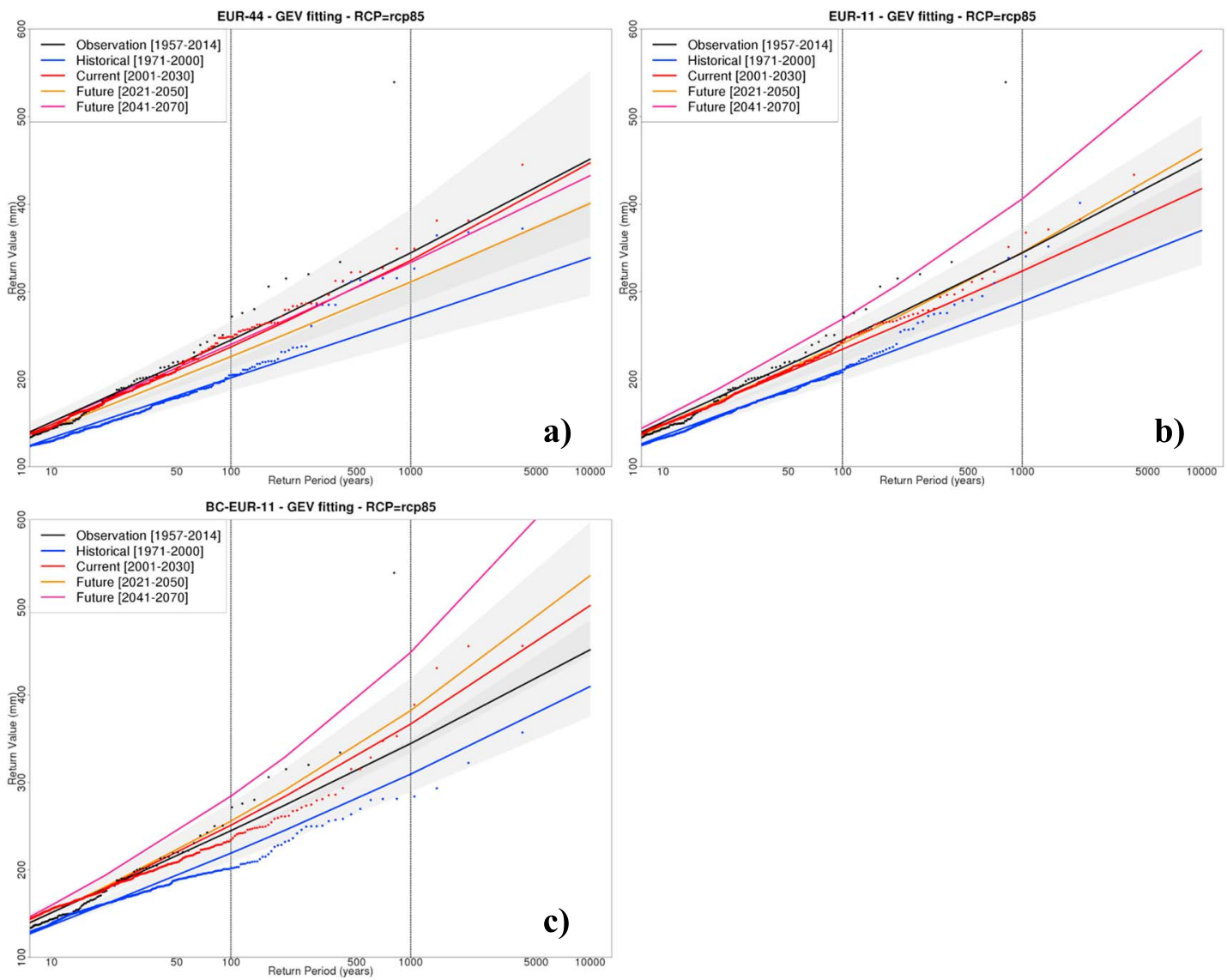

Figure 4. Return level plot from stationary GEV-fitted to model SON maxima of 1-day precipitation; (a) EUR-44, (b) EUR-11, and (c) BC-EUR-11. The blue and red shadings show $95 \%$ confidence interval for historical and current climate, respectively. GEV = generalized extreme value; SON $=$ September-November.

event appears to increase $16 \%$ in current climate compared to historical climate. The uncertainty in this circumstance ranges from $10 \%$ to $24 \%$. When taking rarer events, the significance of results becomes lower in most experiments. For a 1-in-1,000-year event, the intensity of Rx1day increase $7 \%$ ( $-19 \%$ to 51\%) from the EUR-44 ensemble and the return period of this event decreases by a factor of 1.7 (0.4 to 14.9) under current climate. For EUR-11, the likelihood of occurrence of events of comparable intensity to a 1-in-1,000-year event in historical climate may increase by a factor of $1.4(0.7$ to 4.5$)$ in the current climate. The magnitude of this event increases by $8 \%$ within a range of -16 and $29 \%$. For BC-EUR-11, the increase in intensity of a 1 -in-1,000-year event is $37 \%$ (4\% to $63 \%$ ). The likelihood of this event in current climate increases by a factor of 3.1 with a range of 1.8 to 7.1 .

The change in likelihood (Table S4) and intensity of extreme daily events (Table S5) is consistent among three ensembles for return periods lower than 100 years. The $95 \%$ confident interval in these cases are similar, but BC-EUR-11 provides the most robust result. However, the higher return period (e.g., 1,000 years) shows less agreement in changes given their uncertainty margin, specifically the change in intensity. The most reliable increase is produced by BC-EUR-11 ensemble because there are at least three to four models contributing to the tail of pooled distribution.

Generally, all three ensembles show an increase in both intensity and probability (exceedance probability) of extreme rainfall under current climate, although not all are significant. This agrees well with the results of Vautard et al. (2015) which were obtained from observational data sets only. They find that the return period of a 1-in-1,000-year event of climate of 1950 may have decreased by a factor of 4 under climate of 2014 and for a 1-in-100-year event, it might decline by a factor of about 2. There is a small difference between our study and Vautard et al. (2015) because the periods considered and methods used are not the same. 


\section{Discussion and Conclusion}

We have investigated the changes that occurred over the past 30 years in the likelihood in extreme daily precipitation over the Cévennes mountain range. We first evaluated the capacity of the models to simulate these extreme events, using three ensembles with a different resolution (12 and $50 \mathrm{~km}$ ). We find here that a higher horizontal resolution of the model improves the quality of simulation of precipitation magnitudes because of its ability to capture complex topography and large-scale convection, as this was shown by Prein et al. (2016). We also find that a bias reduction with CDFt using a large-scale gridded data set (WFDEI) as a reference significantly improves the statistical properties of extreme precipitation on daily scale even though reference observation-based data are of relatively low resolution. In addition, a finer grid with bias correction can produce a better dependency (average dependent rate and intensity) of daily rainfall on 2-m temperature. These findings reinforce the confidence in our analysis of changes in the probability and intensity of extreme rainfall event.

The likelihood of occurrence and intensity of extreme daily rainfall events show an increasing trend in the interest region. The increase is found to be more confident with EUR-11 and the most confident with BCEUR-11, especially in more rare events (e.g., 1,000-year event) because these events are produced by at least three to four models. This indicates a robust estimate of the increase of probability. For instance, a 1-in-100year event undergoes a probability change of 2.5 (1.8 to 3.4) and 2.2 (1.1 to 3.1) for BC-EUR-11 and EUR-11, respectively, which are both significant increases in frequency.

The changes between the two time periods used in model simulations can only be explained by the changes in GHGs as no other external factor is changing in most EURO-CORDEX simulations. This difference in GHGs is smaller than the difference between factual and natural simulations, but we can reasonably assume that if a significant human influence can be detected in this case, it would be detected in factual versus natural experiments. These changes are found consistent with the physical relation between the extreme daily precipitation and the increase in regional mean temperature as shown in section 2 . Besides, regional mean temperature is strongly concerned with a larger scale (i.e., subcontinental or continental scale) for which formal attribution studies of anthropogenic forcing on increasing in mean temperature were done (Stott, 2003 and Christidis, Stott, Jones, et al., 2012 for the European continent; Christidis et al., 2010 and Christidis, Stott, Zwiers, et al., 2012 for the Mediterranean basin). We, therefore, confirm that human influence plays an indispensable part in altering the likelihood and intensity of daily extreme rainfall events in the Cévennes mountain area. In addition, we also find the advantage of high resolution in constraining the uncertainty margin of the distribution of extreme precipitation.

These results highlight the importance of the increasing resolution in order to improve the estimation of change in odds of extreme rainfall events. However, further improvements could be obtained using convection-permitting models, which allow computing convective rainfall directly in a small area.

\section{References}

This work was supported by EC grant 162227-EUPHEME. L. N. Luu was supported by the Commissariat à I'Energie Atomique et aux énergies alternatives. The EURO-CORDEX simulation can be found at https://esgfnode.ipsl.upmc.fr/search/cordex-ipsl. multi-scale attribution analysis. Climate Dynamics, 34(7-8), 1139-1156. https://doi.org/10.1007/s00382-009-0615-7
Christidis, N., Stott, P. A., Jones, G. S., Shiogama, H., Nozawa, T., \& Luterbacher, J. (2012). Human activity and anomalously warm seasons in Europe. International Journal of Climatology, 32(2), 225-239. https://doi.org/10.1002/joc.2262

Christidis, N., Stott, P. A., Zwiers, F. W., Shiogama, H., \& Nozawa, T. (2010). Probabilistic estimates of recent changes in temperature: A

Christidis, N., Stott, P. A., Zwiers, F. W., Shiogama, H., \& Nozawa, T. (2012). The contribution of anthropogenic forcings to regional changes in temperature during the last decade. Climate Dynamics, 39(6), 1259-1274. https://doi.org/10.1007/s00382-011-1184-0

Clapeyron, É. (1834). Mémoire sur la puissance motrice de la chaleur. Paris: Jacques Gabay.

Clausius, R. (1850). Ueber die bewegende Kraft der Wärme und die Gesetze, welche sich daraus für die Wärmelehre selbst ableiten lassen. Annalen der Physik, 155(4), 500-524. https://doi.org/10.1002/andp.18501550403

Coles, S. (2001). An introduction to statistical modeling of extreme values (Vol. xiv, p. 208). New York: Springer, London.

Drobinski, P., Ducrocq, V., Alpert, P., Anagnostou, E., Béranger, K., Borga, M., et al. (2014). HYMEX a 10-year multidisciplinary program on the Mediterranean water cycle. Bulletin of the American Meteorological Society, 95(7), 1063-1082. https://doi.org/10.1175/ Bams-D-12-00242.1

Ducrocq, V., Braud, I., Davolio, S., Ferretti, R., Flamant, C., Jansa, A., et al. (2014). HYMEX-SOPI the field campaign dedicated to heavy precipitation and flash flooding in the northwestern Mediterranean. Bulletin of the American Meteorological Society, 95(7), 1083-1100. https://doi.org/10.1175/Bams-D-12-00244.1

Eden, J. M., Wolter, K., Otto, F. E., \& van Oldenborgh, G. J. (2016). Multi-method attribution analysis of extreme precipitation in Boulder, Colorado. Environmental Research Letters, 11(12), 124009. https://doi.org/10.1088/1748-9326/11/12/124009

Fischer, E. M., \& Knutti, R. (2015). Anthropogenic contribution to global occurrence of heavy-precipitation and high-temperature extremes. Nature Climate Change, 5(6), 560-564. https://doi.org/10.1038/nclimate2617 
Haylock, M. R., Hofstra, N., Tank, A. M. G. K., Klok, E. J., Jones, P. D., \& New, M. (2008). A European daily high-resolution gridded data set of surface temperature and precipitation for 1950-2006. Journal of Geophysical Research, 113, D20119. https://doi.org/10.1029/ 2008JD010201

Lenderink, G., \& Attema, J. (2015). A simple scaling approach to produce climate scenarios of local precipitation extremes for the Netherlands. Environmental Research Letters, 10(8), 085001. https://doi.org/10.1088/1748-9326/10/8/085001

Lenderink, G., \& Van Meijgaard, E. (2008). Increase in hourly precipitation extremes beyond expectations from temperature changes. Nature Geoscience, 1(8), 511-514. https://doi.org/10.1038/ngeo262

Meinshausen, M., Smith, S. J., Calvin, K., Daniel, J. S., Kainuma, M. L. T., Lamarque, J. F., et al. (2011). The RCP greenhouse gas concentrations and their extensions from 1765 to 2300. Climatic Change, 109(1-2), 213-241. https://doi.org/10.1007/s10584-011-0156-Z

Michelangeli, P. A., Vrac, M., \& Loukos, H. (2009). Probabilistic downscaling approaches: Application to wind cumulative distribution functions. Geophysical Research Letters, 36, L11708. https://doi.org/10.1029/2009GL038401

Min, S.-K., Zhang, X., Zwiers, F. W., \& Hegerl, G. C. (2011). Human contribution to more-intense precipitation extremes. Nature, 470(7334), 378-381. https://doi.org/10.1038/nature09763

O'Gorman, P. A. (2012). Sensitivity of tropical precipitation extremes to climate change. Nature Geoscience, 5(10), 697-700. https://doi.org/ $10.1038 /$ ngeo1568

Prein, A. F., Gobiet, A., Truhetz, H., Keuler, K., Goergen, K., Teichmann, C., et al. (2016). Precipitation in the EURO-CORDEX $0.11^{\circ}$ and $0.44^{\circ}$ simulations: High resolution, high benefits? Climate Dynamics, 46(1-2), 383-412. https://doi.org/10.1007/s00382-015-2589-y

Ribes, A., Thao, S., Vautard, R., Dubuisson, B., Somot, S., Colin, J., et al. (2018). Observed increase in extreme daily rainfall in the French Mediterranean. Climate Dynamics. https://doi.org/10.1007/s00382-018-4179-2

Ruti, P. M., Somot, S., Giorgi, F., Dubois, C., Flaounas, E., Obermann, A., et al. (2016). Med-Cordex initiative for Mediterranean climate studies. Bulletin of the American Meteorological Society, 97(7), 1187-1208. https://doi.org/10.1175/Bams-D-14-00176. 1

Shi, X., \& Durran, D. (2016). Sensitivities of extreme precipitation to global warming are lower over mountains than over oceans and plains. Journal of Climate, 29(13), 4779-4791. https://doi.org/10.1175/JCLI-D-15-0576.1

Stott, P. A. (2003). Attribution of regional-scale temperature changes to anthropogenic and natural causes. Geophysical Research Letters, 30(14), 1724. https://doi.org/10.1029/2003GL017324

Van der Wiel, K., Kapnick, S. B., van Oldenborgh, G. J., Whan, K., Philip, S., Vecchi, G. A., et al. (2017). Rapid attribution of the August 2016 flood-inducing extreme precipitation in South Louisiana to climate change. Hydrology and Earth System Sciences, 21(2), 897-921. https:// doi.org/10.5194/hess-21-897-2017

Vautard, R., van Oldenborgh, G. J., Thao, S., Dubuisson, B., Lenderink, G., Ribes, A., et al. (2015). Extreme fall 2014 precipitation in the Cevennes Mountains. Bulletin of the American Meteorological Society, 96(12), S56-S60. https://doi.org/10.1175/Bams-D-15-00088.1

Vrac, M., Drobinski, P., Merlo, A., Herrmann, M., Lavaysse, C., Li, L., \& Somot, S. (2012). Dynamical and statistical downscaling of the French Mediterranean climate: Uncertainty assessment. Natural Hazards and Earth System Sciences, 12(9), 2769-2784. https://doi.org/10.5194/ nhess-12-2769-2012

Weedon, G. P., Balsamo, G., Bellouin, N., Gomes, S., Best, M. J., \& Viterbo, P. (2014). The WFDEl meteorological forcing data set: WATCH forcing data methodology applied to ERA-Interim reanalysis data. Water Resources Research, 50, 7505-7514. https://doi.org/10.1002/ 2014WR015638

Westra, S., Fowler, H. J., Evans, J. P., Alexander, L. V., Berg, P., Johnson, F., et al. (2014). Future changes to the intensity and frequency of short-duration extreme rainfall. Reviews of Geophysics, 52, 522-555. https://doi.org/10.1002/2014RG000464

Zhang, X. B., Wan, H., Zwiers, F. W., Hegerl, G. C., \& Min, S. K. (2013). Attributing intensification of precipitation extremes to human influence. Geophysical Research Letters, 40, 5252-5257. https://doi.org/10.1002/grl.51010 